\title{
SELING
}

Jurnal Program Studi PGRA

ISSN (Print): 2540-8801; ISSN (Online):2528-083X

Volume 5 Nomor 2 Juli 2019

P. 190-198

\section{PENGARUH PERMAINAN OUTBOUND TERHADAP PERKEMBANGAN SOSIAL ANAK DI TAMAN KANAK- KANAK KEMALA BHAYANGKARI 03 ALAI PADANG}

Aisyah Rahmadani ${ }^{1}$, Yaswinda ${ }^{2}$

Fakultas Ilmu Pendidikan Universitas Negeri Padang

Email: Aisyahrahmadani30@gmail.com

\begin{abstract}
Abstrak: The purpose of this study was to determine the effect of outbound games on the social development of children in kindergarten Kemala Bhayangkari 03 Alai Padang. This research is a quantitative study with a Quasi Experiment approach. The population of this research was all children in Kemala Bhayangkari 03 Alai Padang Kindergarten, Purposive sampling technique, namely class B5 and B6, each of which amounted to 12 children. Data collection techniques using observation. Then the data is processed with a difference test (t-test). Based on data analysis, the experimental class test average was 82.81 and SD was 6.81 while the control class was 69.27 and SD was 5.96 on the hypothesis testing obtained $t$ count (4.97794 and t table 2), 07387 ) at the real level $\alpha=0.05$ and $\mathrm{dk}=22$. It can be concluded that outbound games affect the social development of children in kindergarten Kemala Bhayangkari 03 Alai Padang in the 2018/2019 school year.
\end{abstract}

Keyword: Outbound Games, Social Development of Children.

\begin{tabular}{ccc} 
Submission & Revised & Publication \\
\hline 12 March 2019 & 9 April 2019 & 30 July 2019
\end{tabular}

\section{PENDAHULUAN}

Anak yang berkembang secara optimal adalah anak yang diberi stimulus yang tepat. Perkembangan hidup manusia dimana berbagai aspek yang dimiliki anak mengalami pertumbuhan dan perkembangan yang sangat cepat. Pengalaman akan membentuk kepribadian dan merupakan dasar yang sangat penting pada masa usia dini. Untuk itu stimulus yang tepat sangat dibutuhkan anak, dimana pengalaman secara langsung sebagai sarana untuk mengambangkan berbagai aspek perkembangan tersebut. 
Pendidikan adalah mengembangkan perkembangan anak selaras kemampuannya untuk yang sebaik-baiknya yang dapat dilakukan melalui komunikasi agar anak mencapai kematangan sosial, emosional, intelektual. (Rina Juniarti, Izzati, Yaswinda: 2019). Pendidikan pada masa usia dini adalah pendidikan yang begitu berpengaruh pada masa yang akan datang (Eliza: 2013: 93). Kognitif, bahasa, fisik motorik, moral agama, sosial emosional dan seni merupakan aspek-aspek perkembangan anak yang harus diberikan stimulus pendidikan yang tepat untuk mencapai perkembangan anak yang optimal (Montolalu dkk: 2011). Sejalan dengan hal tersebut suasana bermain yang menyenangkan dapat diterapkan dalam pendidikan anak usia dini dan dalam mendidik anak disesuaikan dengan tahap perkembangan anak (Yaswinda, dkk: 2018).

Pada pembahasan ini yang akan dikembangkan adalah perkembangan sosial anak. Kemampuan berperilaku yang sesuai dengan norma dan nilai lingkungan sosial yang diperoleh seseorang pada proses pembentukan pribadi dalam masyarakat (social self) adalah perkembangan sosial (Susanta: 2010). Westwood (Iman 2014) mengatakan untuk memulai, mempertahankan komunikasi dengan orang yang berada disekitar atau sekeliling kita baik itu teman sebaya ataupun yang lebih tua dari kita adalah keterampilan sosial. Empati, bekerjasama, saling menghargai, saling menghormati, peduli, tenggang rasa, merupakan bagian dari aspek perkembangan sosial (Susanto, 2011:139).

Sebagaimana juga dijelaskan Susanto (2011:40) Agar kematangan social anak tercapai anak terlebih dahulu mempelajari cara menyesuaikan diri dengan lingkungan sekitar. Kemampuan tersebut dapat di dapat anak melalui pengalaman bergaul dengan orang yang berada pada lingkungan sekitarnya seperti saudara, orang tua, orang dewasa maupun teman sebaya anak. Karena sifat social anak belum ada ketika anak dilahirkan, yang berarti anak belum bisa bergaul dengan orang yang berada disekitarnya. Sejalan dengan hal tersebut Syamsu (Marlina: 2013) menjelaskan tecapainya kematangan dalam berkomunikasi dengan orang lain disebut perkembangan sosial. Karena sifat social anak belum ada ketika anak dilahirkan anak sebelumnya harus mempelajari cara-cara menyesuaikan diri dengan lingkungan sekitar (sosialisasi). Setelah itu anak juga belajar beradaptasi terhadap aturanaturan setempat, moral, dan adat istiadat saling bekerjasama dan bersosialisasi menjadi satu. Sejalan dengan pendapat tersebut Yusuf \& Sugandhi (Dewi: 2016) tugas yang membutuhkan pikiran, tenaga fisik, tugas-tugas kelompok merupakan makna kematangan sosial dalam kegiatan belajar di sekolah. Hanita (2017) menjelaskan realisasi dan sosialisasi anak dengan orang yang berada disekitar anak, supaya saling diakui, menghargai dan disayangi atau dicintai merupakan pribadi sosial anak.

Sesuai dengan observasi yang telah peneliti amati di Taman Kanak-kanak Kemala Bhayangkari 03 Alai Padang ditemukan kegiatan dalam mengembangkan sosial anak hanya kegiatan di dalam ruangan atau kelas, seperti anak berkelompok menyelesaikan tugas menyusun balok hingga berbentuk sebuah bangunan (sesuai kreativitas anak). Kegiatankegiatan di luar kelas dalam mengembangkan sosial anak belum ada dilakukan. Melalui penjelasan di atas, perkembangan sosial anak belum berkembang dengan optimal. Seperti sosialisasi dengan teman, kemampuan anak dalam bekerja sama, memahami perbedaan serta rasa empati anak dengan teman sebayanya.

Di lingkungan tempat tinggal anak, anak selalu main sendiri tidak ada teman sebaya yang dapat dijadikan teman maupun sahabat, dan beberapa anak bahkan bermain dengan orang dewasa. Kemudian karena kekhawatiran orang tua, anak tidak bermain di luar rumah maupun bermain-main dengan lingkungan/alam sekitarnya. Tentu saja hal ini dapat menghabat perkembangan sosial anak secara optimal. Sehingga perkembangan sosial anak tidak berkembang dan dengan kurangnya keterampilan sosial yang dimiliki oleh anak, akan berdampak pada perkembangan lainnya. 
Untuk itu, kegiatan outbound adalah kegiatan yang dapat dilaksanakan dalam membantu mengembangkan aspek sosial anak. Menurut Maryatun (Lutfia dkk 2014) Outbound merupakan kegiatan yang berdasarkan perencanaan menantang untuk dilakukan dan dilakukan untuk mencapai perkembangan kemampuan anak. Sejalan dengan hal tersebut Rocmah (2012) belajar melalui pengalaman langsung (experiental learning) yang media penyampaian materinya sebagai petualangan proses belajar mengajarnya dilaksanakan di alam terbuka merupakan program outbound. Handini \& Hasanah (2017) outbound tidak hanya menyediakan permainan dan tujuan tertentu, tetapi juga memberikan berbagai manfaat besar bagi anak. Permatasari (Ananda 2017) mampu bersosialisasi dengan baik, lebih bisa melakukan berbagai hal sendiri dan berbuat sesuai yang diinginkan, lebih mau membantu, menolong dan sensitive dengan perasaan orang lain, meningkatkan rasa ingin akan sesuatu dan memotivikasi agar terus ikut serta dalam kegiatan-kegiatan, mengenali ketahanan, kelemahan diri, menghargai perbedaan, mengungkapkan ekspresi sesuai dengan caranya sendiri namun bisa masuk dalam lingkungan sekitar merupakan tujuan dilakukannya outbound dalam pendidikan. Sesuai dengan uraian yang peneliti paparkan, peneliti tertarik untuk menerapkan outbound untuk mengembangkan sosial anak dengan judul penelitian, Pengaruh Permainan Outbound Terhadap Perkembangan Sosial Anak di Taman Kanak-kanak Kemala Bhayangkari 03 Alai Padang.

\section{METODE}

Bentuk desain yang digunakan adalah Quasi Eksperimen. Tempat penelitian yaitu di Taman Kanak-kanak Kemala Bhayangkari 03 Alai Padang dimulai pada tanggal 01 April 2019. Penelitian ini berusaha melihat dan mengungkapkan adakah pengaruh permainan Outbound terhadap perkembangan sosial anak di Taman Kanak-Kanak Kemala Bhayangkari 03 Alai Padang, dengan membandingkan hasil belajar kelas eksperimen dengan kelas kontrol. Selanjutnya kedua kelompok diberikan tes awal (pre-test). Kemudian setelah itu, kelas eksperimen diadakan perlakuan (X) dengan permainan outbound, sementara pada kelas kontrol tidak diberikan perlakuan atau kemampuan sosialnya dikembangkan dengan cara biasa yaitu dengan pemberian tugas secara berkelompok, selanjutnya kedua kelompok diberikan post-test.

Populasi dalam penelitian ini adalah TK Bhayangkari 03 Alai Padang yang beralamat di Jln Gajah Mada, Kecamatan Padang Utara Padang. TK Bhayangkari 03 Alai Padang memiliki jumlah anak usia dini 101 yang terbagi ke dalam 6 kelompok belajar. Teknik Purposive Sampling ialah teknik pengambilan sampel dalam penelitian ini. Kelompok kelas B5 dijadikan kelompok eksperimen dan kelompok B6 dijadikan kelompok kontrol, ini dijadikan sampel dalam penelitian ini. Ratting scale adalah instrumen penilaian yang peneliti gunakan pada Data penelitian ini.

Uji t (t-tes) adalah teknik analisis data yang peneliti gunakan dalam penelitian ini. Sebelum data diolah, uji liliefors dilakukan terlebih dahulu untuk mengetahui data berdistribusi normal atau tidak, kemudian dilakukan uji normalitas dan homogenitas. Hasil dari uji t (t-tes) tersebut dapat dibandingkan perbedaan dari rata-rata nilai.

\section{HASIL DAN PEMBAHASAN Hasil}

Data dari kedua kelompok yaitu kelompok eksperimen dan kelompok kontrol adalah data yang ada dalam penelitian ini. Penelitian ini dilakukan di Taman Kanak-kanak Kemala Bhayangkari 03Alai Padang. Kelas B5 dan B6 Taman Kanak-kanak Kemala Bhayangkari 03 
Alai Padang yang memiliki jumlah 24 anak adalah populasi. Sampel penelitian terdiri dari kelas eksperimen (Kelas B5) sebanyak 12 orang anak dan kelas kontrol (Kelas B6) sebanyak 12 anak.

Melalui hasil Pre-Test dan Post-Test penelitian diperoleh data penelitian. Pre-Test dan Post-Test penelitian menggunakan 4 butir instrumen, yakni (1) Berkembang Sangat Baik/ BSB diberi skor 4; (2) Berkembang Sesuai Harapan/BSH diberi skor 3; (3) Mulai Berkembang/MB diberi skor 2; (4) Belum Berkembang/BB diberi skor 1.

Kegiatan penelitian pada kelas eksperimen mengembangkan perkembangan sosial anak dengan permainan outbound sedangkan untuk kelas kontrol menggunakan pemberian tugas kelompok menyusun puzzle. Penelitian ini dilakukan sepuluh kali pertemuan, lima kali pertemuan kelompok eksperimen (B5) berawal dari pre-test lalu dilanjutkan tretment tiga kali diakhiri dengan post-test. Kelompok kontrol (B6) lima kali pertemuan berawal dari pretest dan tiga tretment dan diakhiri dengan post-test. Penelitian ini dilakukan dengan tema makanan dan sub tema jenis-jenis makan. Perbandingan nilai hasil perkembangan sosial anak di kelas eksperimen dan kelas kontrol bisa dilihat pada tabel 1.

Tabel 1. Rekapitulasi Hasil Pre-Test Perkembangan Sosial Anak Di Kelas Eksperimen dan Kontrol

\begin{tabular}{|l|l|l|}
\hline \multirow{2}{*}{ Variabel } & Pembelajaran \\
\cline { 2 - 3 } & Eksperimen 1 & Kontrol 1 \\
\hline $\mathrm{N}$ & 12 & 12 \\
\hline Nilai Tertinggi & 68,75 & 62,5 \\
\hline Nilai Terendah & 50 & 50 \\
\hline Jumlah Nilai & 693,75 & 668,75 \\
\hline Median & 56,5 & 57 \\
\hline Rata-rata & 57,81 & 55,73 \\
\hline SD & 5,77 & 4,74 \\
\hline SD $^{2}$ & 33,37 & 22,73 \\
\hline
\end{tabular}

Berdasarkan tabel 1, kelas eksperimen dimana disini jumlah anak 12 orang mendapatkan nilai tertinggi 68,75 dan nilai terendah 50. Dari nilai anak kelas eksperimen ini didapatkan jumlah nilai keseluruhan 693,75, median 56,5 dan 57,81 nilai rata-ratanya, 5,77 standar diviasinya dan 33,37 variansnya. Sementara kelas kontrol jumlah anak ada 12 orang mendapatkan nilai tertinggi 62,5 dan nilai 50 nilai terendah. Jumlah seluruhnya nilai anak pada kelas kontrol didapatkan 668,75, median 57 dan rata-rata nilainya sebesar 55,73 standar diviasinya 4,74 dan nilai variansnya 22,73 .

Sesuai gambaran pada tabel 1 dapat diketahui bahwa perkembangan sosial anak kelas eksperimen hampir sama dengan kelas kontrol. Untuk melihat perbandingan nilai perkembangan sosial anak di kelas eksperimen digunakan kegiatan permainan outbound dan kelas kontrol pemberian tugas kelompok menyusun puzzle.

Tabel 2. Rekapitulasi Hasil Post-Test Perkembangan Sosial Anak Di Kelas Eksperimen Dan Kontrol

\begin{tabular}{|l|l|l|}
\hline \multirow{2}{*}{ Variabel } & Pembelajaran \\
\cline { 2 - 3 } & Eksperimen 1 & Kontrol 1 \\
\hline $\mathrm{N}$ & 12 & 12 \\
\hline Nilai Tertinggi & 93,75 & 81,25 \\
\hline Nilai Terendah & 75 & 62,5 \\
\hline
\end{tabular}




\begin{tabular}{|l|l|l|}
\hline Jumlah Nilai & 993,75 & 831,25 \\
\hline Median & 82,5 & 69 \\
\hline Rata-Rata & 82,81 & 69,27 \\
\hline SD & 6,81 & 5,96 \\
\hline SD $^{2}$ & 46,38 & 35,53 \\
\hline
\end{tabular}

Sesuai gambaran pada tabel 2 dapat diketahui bahwa perkembangan sosial anak kelas eksperimen lebih tinggi daripada kelas kontrol. Untuk menguji hipotesis digunakan $t$ test. Melalui t-test menggunakan uji hipotesis didapatkan hasil sebagai berikut:

Tabel 3. Hasil Perhitungan Pre-Test Pengujian dengan $t$-test

\begin{tabular}{|l|l|l|l|l|l|l|}
\hline No & Kelompok & $\mathbf{N}$ & $\begin{array}{l}\text { Hasil } \\
\text { Rata-rata }\end{array}$ & $\mathbf{T}_{\text {hitung }}$ & $\begin{array}{l}\mathbf{T}_{\text {tabel }} \\
\mathbf{0 , 0 5}\end{array}$ & Keputusan \\
\hline 1 & Eksperimen & 12 & 57,81 & & & \\
\hline 2 & Kontrol & 12 & 55,73 & 0,9244 & 2,07387 & Terima $\mathrm{H}_{\boldsymbol{o}}$ \\
\hline
\end{tabular}

Melalui tabel 3 di atas dengan $\mathrm{dk}\left(\mathrm{N}_{1}-1\right)+\left(\mathrm{N}_{2}-1\right)=22$. Dalam tabel df untuk taraf nyata $=0,05(5 \%)$ di dapat harga $\mathrm{t}_{\text {tabel }}=2,07387$, jadi $\mathrm{t}$ hitung lebih kecil dari $\mathrm{t}$ tabel $(\mathbf{0 , 9 2 4 4}<\mathbf{2 , 0 7 3 8 7 )}$. Dapat disebutkan tidak terdapat perbedaan yang signifikan antara hasil kemampuan awal (pre-test) anak di kelas eksperimen dan kelas kontrol dalam mengembangkan perkembangan sosial anak karena hipotesis $\mathrm{H}{ }_{a}$ ditolak atau $\mathrm{H} o$ diterima. Melalui hasil uji hipotesis dengan menggunakan $t$-test didapatkan hasil sebagai berikut:

Tabel 4. Hasil Perhitungan Post-test Pengujian dengan $t$-test

\begin{tabular}{|l|l|l|l|l|l|l|}
\hline No & Kelompok & $\mathbf{N}$ & $\begin{array}{l}\text { Hasil } \\
\text { Rata-rata }\end{array}$ & $\mathbf{t}_{\text {hitung }}$ & $\begin{array}{l}\mathbf{t}_{\text {tabel }} \\
\mathbf{0 , 0 5}\end{array}$ & Keputusan \\
\cline { 1 - 4 } & Eksperimen & 12 & 82,81 & & & \\
\hline 2 & Kontrol & 12 & 69,27 & 4,97794 & 2,07387 & H ${ }_{o}$ ditolak \\
\hline
\end{tabular}

Melalui tabel tesebut $\mathrm{dk}\left(\mathrm{N}_{1}-1\right)\left(\mathrm{N}_{2}-1\right)=22$. Dalam tabel df untuk taraf nyata $=0,05$ $(5 \%)$ didapat harga $t_{\text {tabel }}=2,07387$, jadi $t_{\text {hitung }}$ lebih besar dari $t_{\text {tabel }}(4,97794>2,07387)$. Dapat disebutkan terdapat pengaruh yang signifikan dengan permainan outbound terhadap perkembangan sosial anak di Taman Kanak-kanak Kemala Bhayangkari 03 Alai Padang karena hipotesis $\mathrm{H}_{a}$ diterima atau $\mathrm{H}_{o}$ ditolak.

Terlihat pada nilai tertinggi dan nilai terendah kelas eksperimen dan kelas kontrol melalui hasil hitung nilai pre-test dibandingkan nilai post-test dimana pada post-test dengan rata-rata 82,81 jadi meningkat rata-rata pre-test setelah diberikan perlakuan (treatment). Selanjutnya bisa dilihat pada grafik 7. 


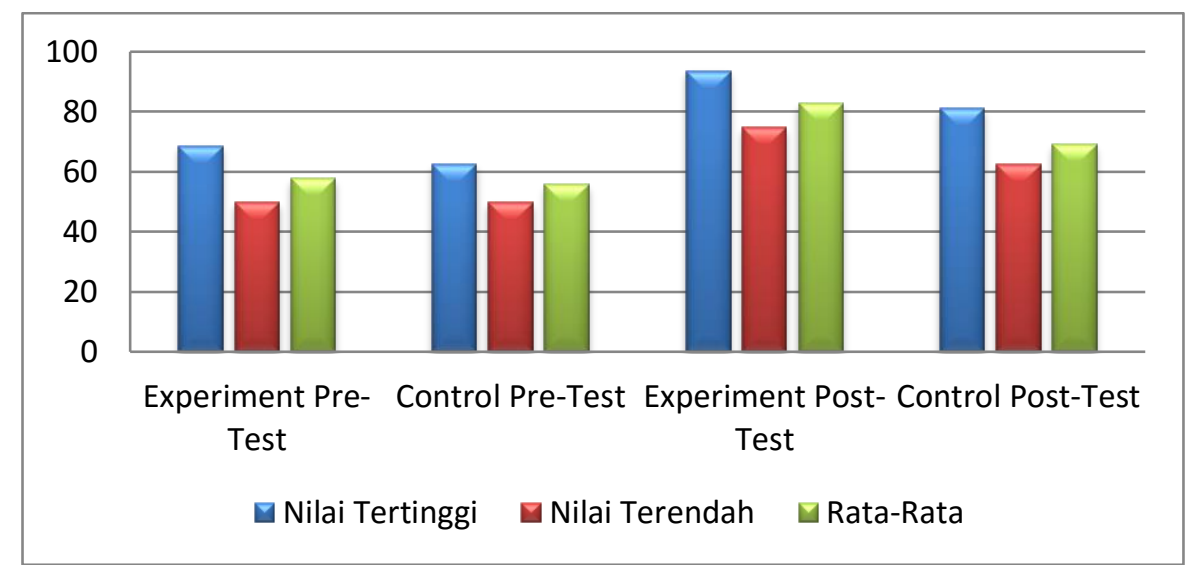

Grafik 7. Data Perbandingan Hasil Pre-Test Dan Post-Test Perkembangan Sosial Anak Kelas Eksperimen B5 Dan Kelas Kontrol B6

Dapat disebutkan perkembangan sosial anak lebih berpengaruh melalui permainan outbound, dibandingkan dengan pemberian tugas secara berkelompok, kelompok eksperimen rata-rata anak mencapai 82,81 dan kontrol 69,27.

\section{Pembahasan}

Dilihat dari hasil pre-test perkembangan sosial anak pada kelas eksperimen dan kelas kontrol pada pre-test didapakan angka rata-rata 57,81 pada kelas eksperimen dan rata-rata 55,73 pada kelas kontrol. $\mathrm{t}$ hitung sebesar 0,9244 dibandingkan dengan $\alpha=0,05(\mathrm{t}$ tabel $=$ 2,07387) dengan derajat kebebasan $d k\left(\mathrm{~N}_{1}-1\right)+\left(\mathrm{N}_{2}-1\right)=22$ melalui hasil analisis data yang telah dilakukan. Bisa disebutkan hipotesis $\mathrm{H}_{a}$ ditolak dan $\mathrm{H} o$ diterima berdasarkan nilai $\mathrm{t}$ hitung $<\mathrm{t}_{\text {tabel }}$ yaitu $(0,9244<\mathbf{2 , 0 7 3 8 7})$.

Hasil post-test perkembanagan sosial anak pada kelas eksperimen dan kelas kontrol pada post-test didapatkan 82,81 angka rata-rata kelas eksperimen dan 69,27 rata-rata kelas kontrol. $\mathrm{t}$ hitung sebesar 4,97794 dibandingkan dengan $\alpha=0,05(\mathrm{t}$ tabel $=\mathbf{2 , 0 7 3 8 7})$ dengan derajat kebebasan $\mathrm{dk}\left(\mathrm{N}_{1}-1\right)+\left(\mathrm{N}_{2}-1\right)=22$ melalui hasil analisis data yang telah dilakukan. Dengan demikian $\mathrm{t}_{\text {hitung }}>\mathrm{t}$ tabel yaitu $\left(4,97794>2\right.$,07387), dapat disebutkan hipotesis $\mathrm{H}_{a}$ diterima atau $\mathrm{H}_{o}$ ditolak. Bisa disebutkan terdapat pengaruh signifikan dengan permainan outbound terhadap perkembangan sosial anak di Taman Kanak-kanak Kemala Bhayangkari 03 Alai Padang. Sejalan dengan hasil tersebut Mayangsari (2017) outbound bertujuan dalam mengembangkan sosial anak "agar dapat meningkatkan kemampuan individu dalam berkomunikasi dengan teman sebaya dan orang yag berada disekitarnya dengan baik dan menolong diri sendiri meningkatkan kecakapan".

Berdasarkan penelitian yang peneliti lakukan terlihat hubungan hasil pre-test dan posttest. 57,81 rata-rata hasil pre-test pada kelas eksperimen dan rata-rata kelas kontrol 55,73. Setelah diberikan perlakuan (treatment) terlihat hasil post-test perkembangan sosial anak pada kelas eksperimen dengan permainan outbound lebih berkembang dengan rata-rata 82,81 sedangkan pada kelas kontrol dengan pemberian tugas secara berkelompok memperoleh rata-rata 69,27. Dapat disimpulkan bahwa hasil pre-test dibandingkan hasil post-test perkembangan sosial kelas eksperimen juga kontrol.

Greenfield, Suzuki, \& Rothstein Fisch; Shweder dkk (Santrock: 52) menyatakan sesuai dengan teori Vygotsky tentang perkembangan sosial dengan pendekatan konstruktivisnya menegaskan bahwa belajar anak adalah melewati komunikasinya dengan orang lain atau orang yang berada disekitarnya. Belajar berkomunikasi anak dapat dipengaruhi oleh budaya 
setempat atau dimana anak tersebut berada, yang berkaitan dengan bahasa, keyakinan, dan keterampilan.

Sebagaimana juga dijelaskan oleh Syamsu (Marlina: 2013) tercapainya kematangan dalam berkomunikasi dengan orang lain atau orang yang berada di lingkungan sekitar disebut perkembangan sosial. Karena sifat social anak belum ada ketika anak dilahirkan, anak sebelumnya harus mempelajari cara-cara menyesuaika diri dengan lingkungan sekitar (sosialisasi) Setelah itu anak juga mempelajari beradaptasi terhadap aturan-aturan setempat, moral dan adat istiadat saling bekerjasama dan bersosialisasi menjadi satu. Sejalan dengan hal tersebut Hanita (2017) mengatakan relisasi dan sosialisasi anak dengan orang lain untuk dicintai, diakui, saling menghargai merupakan pribadi sosial anak.

Menurut Maryatun (Lutfia dkk 2014) outbound merupakan kegiatan yang berdasarkan perencanaan menantang utuk dilakukan dan dilakukan untuk mencapai perkembangan kemampuan anak. Permatasari (Ananda 2017) mampu bersosialisasi dengan baik, bisa melakukan berbagai hal sendiri dan berbuat sesuai yang diinginkan, lebih mau membantu, menolong dan sensitive dengan perasaan orang lain, meningkatkan rasa ingin akan sesuatu dan memotivikasi agar terus ikut serta dalam kegiatan-kegiatan, mengenali ketahanan, kelemahan diri, menghargai perbedaan, mengungkapkan ekspresi sesuai dengan caranya sendiri namun masih bisa masuk dalam lingkungan sekitar merupakan tujuan dilakukannya outbound dalam pendidikan. Melalui kegiatan permainan outbound ini kita dapat mengembangkan perkembangan sosial anak melalui permainan-permainan yang dilakukan diluar ruangan. Yang mana disini permainan outbound yang diujicobakan pertama adalah Lingkar Konsentrasi (Muchlisisn 2009:45-46), tujuannya membangun kebersamaan dan menciptakan kehangatan/keakraban. Kedua, permaianan outbound Estafet Gelang Karet (Muchlisin 2009:49-50) tujuannya adalah membangun kerjasama dan kekompakan anak, melatih kecepatan dan adanya kompetisi anatara anak. Ketiga, permainan outbound Darat, Laut, dan Udara tujuannya menghangatkan/ menyegarkan suasana, dan persepsi atau kemampuan menanggapi sesuatu.

Pada kelompok eksperimen untuk mengetahui kemampuan awal anak dengan menjelaskan satu persatu permainan dan anak antusias ingin mecobakan permainan tersebut. Sedangkan pada kelas kontrol untuk mengetahui kemampuan awal anak yaitu dengan menstimulasi macam-macam pertanyaan tentang tema makanan dan minuman, disini dapat dilihat perkembangan sosial anak belum berkembang dengan optimal. Seperti sosialisasi dengan teman, kemampuan anak bekerjasama, serta rasa empati anak dengan teman sebayanya dan anak kurang antusias dengan pemberian tugas secara berkelompok menyusun puzzle.

Dalam penelitian ini, peneliti menggunakan beberapa item instrumen kelas eksperimen dan kelas kontrol anatara lain anak mampu menunjukkan sikap peduli terhadap teman, anak mamapu menunjukkan sikap mau membantu teman, anak mampu menunjukkan perilaku rendah hati dan santun kepada teman (anak mengucapkan terimakasih karena dibantu temannya), anak mampu menunjukkan sikap bekerjasama dengan teman.

Setelah dilakukan treatment dengan kegiatan permainan outbound pada kelas eksperimen tersebut dilakukan dengan kegiatan yang menyenangkan dan tidak membosankan karena dengan kegiatan permainan outbound dapat bermain diluar ruangan dan mengekspresikan dirinya. Sedangkan pada kelas kontrol anak tidak bersemangat dalam melakukan kegiatan pemberiatan tugas secara berkelompok menyusun puzzle, pada saat penelitian terlihat berbeda antara kelompok kelas eksperimen dan kelompok kelas kontrol terkait keantusiasan anak dalam proses belajar, pada kelas eksperimen menggunakan kegiatan permainan outbound, anak sangat antusias dalam melakukan permainan karena permainan menyenangkan membuat anak bersemangat dan permainan juga dilakukan di 
luar ruangan, masing-masing anak diberikan alat permaina yaitu pada saat bermain estafet gelang karet ada karet dan sedotan agar anak juga mengetahui guna dari sedotan dan karet.

Sedangkan kelas kontrol (B6) menggunakan kegiatan pemberian tugas secara berkelompok dengan menyusun puzzle yang biasa digunakan guru dalam mengembangkan perkembangan sosial anak. Pemberian tugas secara berkelompok dengan menyusun puzzle dilakukan 1 kali dalam seminggu dan itu itu saja, sebagian besar anak kurang antusias dalam mengerjakannya. Jadi kegiatan permainan outbound berpengaruh pada perkembangan sosial anak usia dini dapat terlihat saat anak begitu antusias dan bersemangat dalam bermain lingkar konsentrasi, estafet gelang karet dan darat, laut, dan udara.

Lebih berpengaruh hasil perkembangan sosial anak dikelas eksperiemen dibandingkan hasil perkembangan sosial anak dikelas kontrol, bisa diamati melalui rata-rata kelas kontrol lebih rendah daripada kelas eksperimen. Bedasarkan hal tersebut diambil kesimpulan bahwa terdapat perbedaan yang signifikan antara perkembangan sosial di kelas eksperimen dan kelas kontrol membuktikan kegiatan permainan outbound berpengaruh terhadap perkembangan sosial anak.

\section{SIMPULAN}

Dapat disimpulkan melalui hasil analisis data yang telah diperolah berdasarkan hasil nilai kelas eksperimen ditemukan nilai lebih tinggi dengan rata-rata 82,81 dengan outbound dibandingkan dengan kelas kontrol dengan rata-rata 69,27 dengan pemberian tugas secara berkelompok menyusun puzzle. Dengan uji signifikan pada taraf $\alpha 0,05$ dan $\mathrm{dk}=22$ ditemukan $\mathrm{H}_{\mathrm{a}}$ 4, 97794 pada nilai $t$ tabel 2,07387. Sehingga terbukti berpengaruh. Dengan demikian dapat disimpulkan bahwa kegiatan permainan outbound berpengaruh dalam mengembangkan perkembangan sosial di Taman Kanak-kanak Kemala Bhayangkari 03 Alai Padang.

\section{SARAN}

Peneliti berharap melalui permainan outbound dapat mengembangkan perkembangan sosial anak dengan sebaik-baiknya dan guru juga harus menciptakan kegiatan yang bervariasi juga media yang berbeda-beda, kegiatan yang dilakukan tidak hanya kegiatan didalam kelas melainkan juga diluar ruangan atau diluar kelas. Melalui aktivitas maupun permainan yang lebih menarik. Salah satunya kegiatan pembelajaran yang dapat digunakan adalah permainan outbound. Bagi kepala sekolah, dalam mengembangkan pembelajaran khususnya pengembangan sosial hendaknya sekolah dapat memberikan arahan, motivasi serta dorongan kepada guru untuk menciptakan inovasi-inovasi baru dalam kegiatan pembelajaran untuk mengembangkan sosial anak. Bagi peneliti selanjutnya, diharapkan dapat meneliti dan menyampaikan gagasan tentang pembelajaran yang digunakan dalam mengembangkan sosial anak serta menjadi inspirasi dalam melakukan penelitian dimasa yang akan datang. 


\section{DAFTAR PUSTAKA}

Hanita. 2017. Identifikasi Perkembangan Sosial dan Emosi di Sekolaah Berdasarkan Pola Asuh Pada Anak Usia 4-6 Tahun.http://journal.umpo.ac.id/index.php/indria/index

Handini, Myrnawati C, Hasanah Linda Nur.2017.The Enhancement Adversity Quotient Through Outbound Play Activities. http://creativecommons.org/licenses/bync/4.0/. Vol 58

Iman, Esra Deleri.2014. The Effect of the values Education Programme on 5.5-6 Year Old Children's Social Development: Social Skills, Psyco-social Development and Social Problem Solving Skills. http://web.b.ebscohost.

Isbayani, Nur Shintya dkk. 2015. Penerapan Metode Outbond Untuk Meningkatkan Keterampilan Sosial Emosional Anak. http://ejournal.undiksha.ac.id Volume 3 no 1.

Istiqomah, Nurul dkk. 2016. Peningkatan Perkembangan Sosial Emosional Melalui Kegiatan Outbond pada Anak Kelompok B di TK Asy-Syafa'ah Jember Tahun Pelajaran 2015/2016. http://jurnal.unej.ac.id/index/php/JUJE/Article.

Lutfia,dkk.2014.Pengaruh Outbound Terhadap Kecerdasan Moral Anak Sekolah Dasar. http://ejournal.unp.ac.id/index.php/ Vol 5 No 2 November 2014

Marlina, Serli. 2013. Pengembangan Perangkat Pembelajaran Sikap Sosial Multikultural Melalui Permainan Puzzle Pada Pendidikan Anak Usia Dini. http://ejournal.unp.ac.id/index.php/pedagogi/article/view/2227 Vol XIII No.1 April 2013.

Mayangsari, Dewi dkk. 2017. Peningkatan Perilaku Prososial Pada Anak Usia 4-5 Tahun Melalui Kegiatan Outbond Fun Estafet Di Tk PGRI Burneh Bangkalan. http://journal.trunojoyo.ac.id/pgpaudtrunojoyo.

Muchlisin, Badiatul. 2009. Fun Outbound Merancang Kegiatan Outbound yang Efektif.Jogjakarta:DIVA Press

Rocmah, Luluk Iffatur.2012.Model Pembelajaran Outbound Untuk Anak Usia Dini. https://ojs.umsida.ac.id Vol. 1 No. 2 Juni 2012

Santrock, John.W. 2009. Psikologi Pendidikan.(Edisi ke-3).Terjemahan oleh Diana Angelica Jakarta: Salemba Humanika

Poppyarriyana, Alfian Ashshidioi. 2013. Pengaruh Permainan Outbound Terhadap Kemampuan Kerjasama Pada Anak Kelompok B TK Aisyiyah 20 Pajang Tahun Pelajaran 2012/2013.http://emprints.ums.ac.id/24860/15/02.pdf.

Sugiono. 2012. Metode Penelitian Pendidikan Pendekatan Kuantitatif, Kualitatif, dan R\&D (cetakanke15). Bandung:Alfabeta.

Susanto, Ahmad. 2011. Perkembangan Anak Usia Dini. Jakarta: Kencana

Yaswinda, dkk. 2018. Pengembangan Bahan Pembelajaran Sains Berbasis Multisensori Ekologi Bagi Guru PAUD Kecamatan Tilatang Kamang Kabupaten Agam https://jurnal.umj.ac.id ISSN: 2580-4197 Vol 2 No II November 2018 